\title{
SÍLVIA LANE E O PROJETO DO "COMPROMISSO SOCIAL DA PSICOLOGIA"
}

\author{
Ana Mercês Bahia Bock \\ Pontifícia Universidade Católica de São Paulo, São Paulo, Brasil \\ Marcos Ribeiro Ferreira \\ Universidade Federal de Santa Catarina, Florianópolis, Brasil \\ Maria da Graça M. Gonçalves \\ Odair Furtado \\ Pontifícia Universidade Católica de São Paulo, São Paulo, Brasil
}

\begin{abstract}
RESUMO: Este artigo apresenta os principais aspectos da trajetória da Profa. Sílvia Tatiana Maurer Lane, desde a construção de uma Psicologia Social crítica até a formulação de um projeto de compromisso social da Psicologia. A Profa. Sílvia Lane foi pioneira nas formulações teóricas que colocaram a Psicologia Social brasileira em questão, ressaltando a necessidade de se explicitar seu vínculo com interesses dominantes e de se redirecionar sua produção no sentido de contribuir para a transformação social. Nessa trajetória aliou teoria e prática, contribuindo para a revisão de conceitos e métodos e para a organização da área. Trabalhou incansavelmente e em várias frentes para produzir uma Psicologia Social que reconhecesse o caráter histórico dos fenômenos sociais e humanos e a pessoa como sujeito ativo e histórico. Inicialmente o artigo relata sua presença marcante, dentro dessa perspectiva, na história da Psicologia Social brasileira e latino-americana. A seguir, são apontadas as principais características de sua produção teórica na elaboração de uma Psicologia Social sócio-histórica. Por fim, discute-se seu importante papel na afirmação de uma psicologia comprometida com as realidades brasileira e latino-americana; conhecedora dessa realidade, contribuiu para a construção de instrumental teórico-prático para sua transformação na direção de uma sociedade justa e igualitária. Ou seja, uma psicologia com compromisso social.
\end{abstract}

PALAVRAS-CHAVE: Psicologia Sócio-Histórica; compromisso social; história da Psicologia Social.

\section{SÍLVIA LANE AND THE PROJECT FOR A SOCIALLY COMMITTED PSYCHOLOGY}

ABSTRACT: This article presents the main aspects of the academic trajectory of Professor Sílvia Tatiana Maurer Lane, from the initial proposal of a critical Social Psychology to the formulation of a project for a socially committed Psychology. Sílvia Lane was a pioneer in theoretical propositions which questioned mainstream Brazilian Social Psychology, emphasizing the need to expose its ties with the dominant economic and political interests and redirecting its production towards social transformation. In her career trajectory she brought together theory and praxis, contributing to the revision of concepts and methods, and to the organization of this area of knowledge. She worked tirelessly in various fronts to produce a Social Psychology that could recognize the historical character of social and human phenomena and that conceived people as active and historical beings. The text begins by situating her remarkable presence, within this critical perspective, in Brazilian and Latin American Social Psychology. In sequence, it presents the main characteristics of her theoretical production concerning the development of a Socio-Historical Social Psychology. At the conclusion, it emphasizes her role in consolidating a Psychology that is intrinsically compromised with Brazilian and Latin-American realities; being familiar with this reality, she contributed to the construction of theoretical-practical instruments for its transformation in the direction of a society based on justice and equality. To put is in a different manner, the development of a socially committed Psychology.

KEYWORDS: Socio-Historical Psychology; social compromise; history of Social Psychology.

A professora Sílvia Tatiana Maurer Lane tem uma trajetória de vida profissional, no campo da Psicologia Social, que faz dela uma das mais importantes influências no desenvolvimento de um novo projeto para a Psicologia: o projeto do compromisso social. Seu trabalho, sempre aliado ao de outras pessoas, produziu novos caminhos para a Psicologia. Sua produção teórica permitiu a construção de novas perspectivas no campo da Psico- logia Social, sendo responsável pelo desenvolvimento da perspectiva sócio-histórica na Psicologia Social no Brasil. Suas idéias sobre a prática permitiram a construção da Psicologia Social Comunitária. Seu empenho na América Latina criou intercâmbios e trocas, fortalecendo o diálogo no campo da Psicologia entre profissionais deste continente. Seus princípios permitiram apoio na construção de um novo projeto de Psicologia. 
Sílvia Lane foi guiada pelo princípio de que o conhecimento produzido deveria sempre ser útil para a transformação da realidade na direção da criação de condições dignas de vida para todos. O conhecimento e a profissão deveriam estar a serviço da transformação e, com estas idéias, Sílvia Lane contribuiu para uma revolução na Psicologia. Com o rompimento com a tradição elitista da Psicologia, com a preocupação com a construção de um novo projeto para a ciência e para a profissão, com a adesão a uma nova concepção de homem para a Psicologia e com o esforço para aproximar a América Latina, Sílvia Lane apontou as exigências e condições para um novo projeto para a Psicologia. E desta forma, pode-se apontar Sílvia Lane como uma das influências do que hoje se denomina de Projeto do Compromisso Social da Psicologia. Trabalho coletivo, consciência crítica e atenção permanente e comprometida com as urgências e necessidades da população se puseram como pedras fundamentais da transformação da Psicologia e, não há dúvida, da importância de Sílvia Lane neste caminhar. Foi professora na Pontifícia Universidade Católica de São Paulo (PUC-SP) e seu trabalho naquela Universidade merece ser resgatado, pois é a partir dali que se expandem sua influência, suas idéias e seus convites para que um coletivo dos psicólogos se engajasse nas novas tarefas. No Brasil, muitos aceitaram o convite de Sílvia Lane para esta empreitada e podem-se encontrar marcas desta contribuição espalhadas por todo lugar onde há psicólogos. Importante registrar que este coletivo se tornou diversificado e rico, porque Sílvia Lane entendia também que a partir de algumas idéias e princípios é possível e desejável esperar do outro sua produção original. Neste artigo, quatro alunos de Sílvia Lane, desde a década de 70 na graduação em Psicologia na PUC-SP até os anos 90 nos estudos pós-graduados em Psicologia Social na mesma Universidade, retomam a história, refletindo sobre o caminho percorrido por Sílvia Lane na Psicologia Social brasileira e da América Latina, destacando a corrente da Psicologia Sócio Histórica que se instalou nos espaços onde ela estava na PUC-SP, desenvolveu-se na Faculdade de Psicologia daquela Universidade e contribuiu com a construção dos alicerces do novo projeto de Compromisso Social da Psicologia. Ao se fazer esta retomada, pretende-se prestar uma homenagem à professora que se tornou para todos modelo de rigor científico, de compromisso político e de um "professorar" em permanente movimento, carregado sempre da melhor inquietação.

Inicialmente vamos retomar a história de Sílvia Lane e da Psicologia Social ressaltando a contribuição de Sílvia Lane a partir de seu trabalho na PUC-SP. Em seguida vamos destacar o desenvolvimento da Psicologia Social Sócio-histórica no Brasil e a importância e papel de Sílvia Lane nesta construção. E por fim traremos a idéia de uma Psicologia atenta ao contexto social como sua contribuição a um novo projeto de Psicologia, como ciência e profissão. Em todos estes momentos enfatizaremos os aspectos que, a nosso ver, são fundamento da idéia de compromisso social da Psicologia.

\section{Um Pouco de História}

Sílvia Lane formou-se em 1956 em Filosofia pela Universidade de São Paulo (USP) e começou sua carreira profissional no Conselho Regional de Pesquisa Educacional, ligado ao Ministério da Educação, o qual tinha como finalidade reformular o ensino no Brasil. Sílvia Lane manteve-se no Conselho até 1960. Em 1965, convidada pela Profa. Maria do Carmo Guedes, passou a ministrar aulas no curso de Psicologia da Faculdade de Filosofia, Ciências e Letras São Bento da Pontifícia Universidade Católica de São Paulo, onde também trabalhava Aniela Ginsberg. É neste espaço da PUC-SP que Sílvia Lane construiu toda sua carreira de professora de Psicologia Social. Inicialmente, ligada ao Laboratório de Psicologia Experimental, começou a realizar suas pesquisas em Psicologia Social. Defendeu seu doutorado em 1970 na própria PUC-SP realizando pesquisa sobre o diferencial semântico de Charles Osgood com o título "Significado psicológico de palavras em diferentes grupos socio-culturais". Na sua defesa da tese:

\begin{abstract}
. . Joel Martins provocou Sílvia, observando que ela trabalhara na pesquisa com Osgood mas estava "namorand" Skinner. De fato Sílvia confessa que, apesar de utilizar a escala de diferencial semântico, por considerá-la instrumento preciso, não aceitava a teoria de resíduo de Osgood. Leu muito Skinner para sua pesquisa e sentia mais consistência na sua teoria do que na de Osgood, com uma abertura para o materialismo dentro da Psicologia ... Sílvia nunca se considerou skinneriana, mas a materialidade daquela teoria a atraía muito, e facilitou-lhe o entendimento da Psicologia Social soviética. (Sawaia, 2002, p. 33).
\end{abstract}

No final dos anos 60 e início dos anos 70, a PUC-SP e o Instituto de Psicologia, onde Sílvia Lane era professora, passaram por grandes transformações. Foram momentos importantes de mobilização universitária em prol da reforma e da inovação do ensino superior. Em 1971, foi criada a Faculdade de Psicologia da PUC-SP, a partir da fusão da Faculdade São Bento e do Sedes Sapientiae. Tornou-se a primeira diretora do curso de Psicologia recém criado. Tinha nas mãos o desafio de construir um novo curso de Psicologia e a Profa. Sílvia Lane aceitou o desafio. A estrutura e organização da Psicologia da PUCSP tornar-se-iam referência para os cursos no Brasil.

Era assim que Sílvia Lane definia esse período:

No curso de graduação da PUC-SP, tentávamos concretizar a tese da teoria e prática no ensino, levando os alunos a observações, entrevistas, enfim, a coletar 
dados do cotidiano e confrontá-los com os textos clássicos sobre os conceitos de atitudes, motivação e percepção sociais, dissonância cognitiva, socialização, dinâmica de grupo etc. (Lane, 1999).

A proposta era de chegar a uma revisão crítica dos conceitos. Sílvia Lane entendia que era preciso superar a idéia e o hábito de fazer da realidade um exemplo dos conceitos teóricos. Ter a realidade material como parâmetro era quase uma obsessão para Sílvia Lane, que considerava necessário tomá-la como referência para a produção da ciência. A realidade deveria ser critério para análise da importância e fidedignidade de dados que as pesquisas produziam e não o contrário.

Essa preocupação traduziu-se em postura metodológica, pois o objetivo era produzir conhecimento que possibilitasse uma compreensão da realidade que implicasse, necessariamente, sua transformação. Sílvia Lane foi incansável na produção teórica e de pesquisa com esse norte: conhecimento científico como práxis, unidade entre saber e fazer. Tinha claro que uma nova psicologia social só se configuraria por meio de concepções teóricas fundadas em pesquisa relevante e socialmente comprometida. Para Sílvia Lane, teoria e prática deveriam ser vividas como militância.

No entanto, Sílvia Lane não tinha facilidade de encontrar eco para suas preocupações. Insistentemente, manteve-se como professora de Psicologia Social e ali fazia seu esforço para cultivar novas concepções sobre pesquisa, ciência e Psicologia e procurou ocupar espaços onde estas intenções pudessem ter desenvolvimento. Criou, em 1977, com o Prof. Alberto Abib, contando depois com a participação da Profa. Odette de Godoy Pinheiro, um trabalho em Psicologia nos Sindicatos e comunidades operárias de Osasco em uma disciplina intitulada "A Psicologia Social na prática clínica". A temática era um achado, na medida em que a maioria esmagadora dos alunos da Faculdade de Psicologia da PUC-SP se especializava na área clínica. Esta área, mesmo com o tipo de ensino crítico ministrado ali, apresentava um forte viés individualista. Apesar do compromisso político de boa parte dos professores, o instrumental teórico era voltado para o atendimento nos consultórios privados e a ideologia reproduzida por esse modelo de atendimento era a do psicólogo como profissional liberal. ${ }^{1} \mathrm{O}$ curso ministrado na Faculdade de Psicologia reunia a visão crítica e a militância acadêmica de Sílvia Lane e a militância no movimento operário de Alberto Abib Andery.

Esta experiência, que ocorreu principalmente na cidade de Osasco, cidade pertencente à Grande São Paulo, com certa concentração industrial e com vários bairros operários, leva tanto os alunos nela envolvidos quanto seus professores a uma intensa reflexão sobre os limites da teoria e da prática psicológicas. É esta experiência que lançou as bases daquilo que Sílvia Lane e Bader Sawaia (1995) iriam, mais adiante, chamar de Psicologia Social Comunitária. O relato sistematizado das inúmeras intervenções realizadas nessa ocasião foi apresentado no Primeiro Encontro Regional de Psicologia na Comunidade promovido pela Associação Brasileira de Psicologia Social (ABRAPSO) e pela PUC-SP em 1981. Os anais desse encontro acabaram por se transformar na referência mais freqüentemente citada por todos aqueles que passaram a trabalhar com a psicologia comunitária. $^{2}$

Os trabalhos de Osasco permitiram um profundo questionamento tanto da metodologia quanto da teoria da psicologia social. Recuperou-se a experiência já consagrada de Paulo Freire com sua obra "Pedagogia do oprimido", leu-se Alberto Merani, debateu-se a necessidade e preponderância do método qualitativo de pesquisa, falou-se em pesquisa-ação ou pesquisa participante. Questionou-se profundamente o parâmetro teórico da psicologia social. De uma hora para outra, apenas a discussão crítica da Psicologia Social americana não era mais suficiente. Tratou-se de superar radicalmente uma psicologia por demais comprometida ideologicamente e que não cabia em nossa realidade.

Este processo teve seu início em outras iniciativas também importantes: a disciplina "Estudos livres", no curso de graduação em Psicologia, ministrada pela Profa. Sílvia, permitia livres reflexões sobre o conhecimento e a relação da Psicologia com a realidade social, nos anos 74 e 75. A disciplina ministrada pelo Prof. Abib, "Configuração sócio-psicológica do trabalhador brasileiro", ia na mesma direção. A idéia fixa de relacionar mais de perto a prática com a teoria, permitindo um conhecimento crítico e uma prática consistente, levou Sílvia Lane à proposta de Núcleos como formas organizadoras do curso para o $4^{\circ}$ e $5^{\circ}$ anos da Faculdade de Psicologia. Estávamos em 1974/75. Os núcleos eram práticas profissionais em forma de estágio, acompanhadas de disciplinas teóricas que lhes davam sentido e permitiam a crítica a partir das experiências vividas como exercício e treinamento profissional.

As críticas apontadas por Sílvia Lane e as reflexões produzidas nessas experiências encontraram espaço adequado para seu desenvolvimento, quando se consolidou o programa de estudos pós-graduados em Psicologia Social da PUC-SP. Criado em 1972, com a participação de Sílvia Lane, o programa permitiu a reunião de esforços para a produção de uma nova perspectiva em Psicologia Social. Sílvia ministrou disciplinas que se propunham a fazer revisões críticas de experimentos e pesquisas indexados no Psychological Abstracts. A constatação da inconsistência dos resultados encontrados e de sua 
inadequação a fenômenos sociais presentes na realidade pesquisada no Brasil apontou para um vazio teórico que gerou a certeza de que era urgente o desenvolvimento de pesquisas que levassem a uma nova sistematização.

Sua preocupação básica em construir uma psicologia social voltada para a realidade brasileira e latinoamericana, com vistas a contribuir para a superação das desigualdades e das situações de opressão, demandava uma construção teórica que permitisse compreender o homem como participante do processo social. Nesse sentido, entendia que o conhecimento da psicologia deveria levar à compreensão dos mecanismos que provocam a alienação e contribuir para ampliar a consciência dos homens. Sua teoria sobre o psiquismo teve essa direção.

A obra teórica de Sílvia Lane pode ser lida de várias formas, com diversos recortes. Mas, são fundamentalmente dois aspectos de grande complexidade os que estão na sua base e apontam para essa perspectiva de compreensão do homem: a relação subjetividade e objetividade; e a formação e o papel dos valores. A forma como tratou esses aspectos complexos revela outra marca da produção de Silva Lane: simplicidade de proposições, calcada em pesquisa rigorosa.

A Profa. Sílvia Lane traduziu nessas duas questões a preocupação em investigar e compreender como o indivíduo está implicado com a sua sociedade, como se coloca nela, o que permite ou impede que ele compreenda as determinações sociais e como pode agir sobre elas.

Uma parte de sua discussão caminhou, como vimos acima, pela crítica à psicologia social predominante em nosso meio. Era a psicologia social norte-americana, de base experimental e positivista, que falava de mecanismos psicológicos universais e abstratos, desconsiderando o conteúdo histórico e social presente na constituição do homem.

A psicologia social cognitivista coloca como objeto as relações interpessoais e a influência de fatores sociais no indivíduo, mas estabelecendo uma dicotomia entre indivíduo e sociedade e dentro de uma perspectiva naturalizante. Tais formulações estão baseadas em um método experimental, que busca relações causais entre variáveis e estabelece a necessidade de verificação empírica de princípios teóricos. Baseado no positivismo, o método prega a neutralidade do conhecimento científico e a distinção entre o conhecimento e a ação, ou seja, entende que o conhecimento deve ser objetivo e desvinculado de qualquer intenção em relação a seu uso.

Cada um desses pontos foi questionado e discutido por Sílvia Lane. Seu conhecimento sobre Lewin e Skinner já a levara a questionar a dicotomia entre subjetividade e objetividade. Entendia que ambos traziam contribuições importantes para a compreensão do indivíduo, mas as perspectivas que desvinculavam o indivíduo de seu contexto não eram suficientes para se entender o homem social.

Considerava que, no caso da psicologia social cognitivista, isso era mais grave, pois o que se produzia era uma psicologia que não atentava, realmente, para as questões sociais, já que elas eram apenas "pano de fundo" para os acontecimentos do mundo psíquico.

A aproximação de Sílvia Lane com autores da Psicologia Social de outros países da América Latina foi também essencial em todo este processo.

Foi a partir de 1976 que aqueles que realizavam experiências semelhantes na América Latina passaram a estabelecer contato e, de uma maneira informal, a traçar um programa alternativo para a Psicologia Social de cunho experimental desenvolvida nos Estados Unidos e que até então era dominante também no Brasil. É o caso, entre outros tantos, da peruana Gladys Montecinos, das venezuelanas Maritza Monteiro e Maria Auxiliadora Banchs, do cubano Fernando González Rey e do espanhol radicado em El Salvador, Ignacio Martín-Baró. Silvia Lane analisou e se referiu a este período, trazendo a importância de a Psicologia Social dialogar com outras Psicologias Sociais de países da América Latina, como pode ser visto em entrevista publicada no PSI Jornal de Psicologia do Conselho Regional de Psicologia de São Paulo (CRP-SP) em 2000.

A Psicologia Social no Brasil era um 'zero à esquer$d a$ ', não interferia em nada, não ajudava em nada, quer dizer, era um saber que estava lá, que partia das teorias americanas para explicar a realidade brasileira. Era preciso compreender como o latino-americano singulariza o universal na constituição particular de sua existência. (Lane, 2000).

O trabalho social iniciado no curso de graduação da PUC-SP, o desenvolvimento das pesquisas no curso de pós-graduação e as relações na América Latina se uniram enquanto aspectos fundamentais para a construção da nova perspectiva em Psicologia Social. Uma perspectiva que, segundo Sílvia Lane, deveria começar explicitando uma nova concepção de homem na psicologia: um homem social e histórico. E, para compreender esse homem e como as determinações históricas estão em relação com ele, seria necessário um outro método. O materialismo histórico e dialético será o método que ela vai adotar e desenvolver na psicologia social.

Sem dúvida, o marxismo, como postura epistemológica, estava na minha cabeça, como proposta para superar a ideologização da nossa ciência. E foi um desafio encontrar um eixo marxista para desenvolver uma nova psicologia social (Lane, 2000).

Portanto, juntava-se, aos ingredientes já comentados, o marxismo. Esta perspectiva, como ela mesma disse, 
epistemológica, vai contribuir para a superação do positivismo na forma de fazer ciência, para a elaboração de novos métodos de pesquisa e para a afirmação do homem como sujeito histórico.

A afirmativa de que o positivismo, na procura da objetividade dos fatos, perdera o ser humano decorreu de uma análise crítica de um conhecimento minucioso enquanto descrição de comportamentos que, no entanto, não dava conta do ser humano agente de mudança, sujeito da história. O homem ou era socialmente determinado ou era causa de si mesmo: sociologismo vs biologismo? Se por um lado a psicanálise enfatizava a história do indivíduo, a sociologia recuperava, através do materialismo histórico, a especificidade de uma totalidade histórica concreta na análise de cada sociedade. Portanto, caberia à Psicologia Social recuperar o indivíduo na intersecção de sua história com a história de sua sociedade-apenas este conhecimento nos permitiria compreender o homem como produtor da história. (Lane, 1984a, p. 13).

Essa formulação expressa a elaboração realizada no processo de crítica à psicologia social tradicional e busca de novas referências a que nos referimos acima. Uma nova postura epistemológica, metodológica e ontológica vai subsidiando a constituição de novas categorias e conceitos explicativos do psiquismo.

A partir do materialismo histórico e dialético, Lane produziu, então, uma nova psicologia social, cujo objeto, em vez de "relações interpessoais e influências sociais", como propunha a psicologia social tradicional, seria o homem como ser histórico, a dialética entre indivíduo e sociedade, o movimento de transformação da realidade. $\mathrm{O}$ objetivo era compreender o indivíduo em relação dialética com a sociedade; a constituição histórica e social do indivíduo e os elementos que explicam os processos de consciência e alienação; e as possibilidades de ação do indivíduo frente às determinações sociais.

O método materialista histórico e dialético tem recursos para se compreender o homem dentro da totalidade histórica, a partir das categorias da dialética (totalidade, contradição, empírico-abstrato-concreto, mediação). Além disso, esse método considera que sujeito e objeto estão em relação dialética, portanto não há neutralidade no conhecimento, há sempre uma intenção do sujeito sobre o objeto. Essa intenção é histórica e deve ser considerada.

Em outras palavras, o materialismo histórico e dialético permite trabalhar com a historicidade dos fenômenos e, por isso, contrapõe-se à sua naturalização. Boa parte da obra de Sílvia Lane foi para desenvolver uma compreensão do psiquismo fundamentada nesses pressupostos.

E, de maneira coerente, tais formulações foram produzidas a partir de pesquisas realizadas com métodos adequados à compreensão da realidade como contraditória, em processo de transformação constante e do conhecimento como práxis.

Dentre as novas metodologias destacou-se a pesquisa-ação participante. A concepção de pesquisa participante anulava toda discussão sobre a neutralidade da ciência e do pesquisador. Tratava-se, então, de discutir o compromisso social do pesquisador.

É importante situar no tempo estes esforços. Estávamos nos anos 70, nos "anos de chumbo" da sociedade brasileira e o desenvolvimento de concepções progressistas dentro de algumas Universidades, como a PUCSP, era um fato. Havia clima adequado para as reflexões e críticas que Sílvia Lane propunha, agora já acompanhada de um grupo de professores do Programa de PósGraduação em Psicologia Social (Bader Sawaia, Suely Rolnik, Leonor Gaioto, Antônio Ciampa, Maria do Carmo Guedes, entre outros) e reunindo alunos/ orientandos que buscavam alternativas para a tradicional Psicologia Social (Wanderley Codo (1981), Renate Sanchez (1974), Antonio Ciampa (1977 e 1986), Alfredo Naffah (1983), Carlos Peraro Filho (1978 e 1988), Irede Cardoso (1978), Bader Sawaia (1979 e 1987), Ivanise Leite (1979), Eizabeth Lenza (1981), Maria Lucia Violante (1981), Fernando Pontes (1983), Sylvia Friedman (1985), Brígido Camargo (1985), Elvira Wagner (1986), Sueli Terezinha Martins (1987), Denise Camargo (1988), entre outros).

Sílvia Lane, seus alunos e colaboradores se voltaram, dessa forma, para a tarefa de construir uma alternativa teórica que estivesse consoante com os problemas enfrentados no cotidiano da realidade brasileira. E é importante frisar que essa construção teórica se dava em todos os espaços que Sílvia Lane ocupava como professora, pesquisadora e militante por uma psicologia social crítica.

Ela foi protagonista dessa posição em vários eventos, dentre eles debates com Aroldo Rodrigues, o representante no Brasil da psicologia social cognitivista.

Nos debates, Aroldo Rodrigues afirmava que aquilo que Sílvia Lane fazia não era ciência, era política. Segundo ele “. . . a Psicologia Social é uma ciência básica e neutra, a ela cabe descobrir as relações estáveis entre variáveis psicossociais a fim de possibilitar ao tecnólogo social a solução dos problemas sociais de forma consciente e não improvisada" (Rodrigues, 1986, apud Sawaia, 2002).

Em suas respostas, Sílvia Lane afirmava que: “ . . . o fundamental neste momento é a psicologia rever sua prática, pois teoria e prática têm que vir juntas. Não se pode dividir a psicologia social em ciência aplicada e pura" (Lane, 1986, apud Sawaia, 2002).

No final dos anos 70 Sílvia e seus orientandos realizaram,uma intensa discussão teórico-metodológica no 
Programa de Estudos Pós-Graduados em Psicologia Social da PUC-SP, formalizando e sistematizando o processo de revisão metodológica da Psicologia Social. Nesse processo, foi feita a releitura de George Mead e de Politzer; discutiu-se a crítica feita à psicologia social por Poitou, Bruno e Pêcheux; a partir do livro organizado por Serge Moscovici, Introduction de la Psychologie Sociale, discutiu-se o conceito de Representação Social; também debruçaram sobre as questões da linguagem, analisando e Teorias da Psicologia da Linguagem de Robert Terwilliger. Mas, é com a (re)descoberta de Vigotski, Luria e Leontiev que se tornou possível o salto de qualidade que levou à fundamentação das categorias básicas do psiquismo: a consciência, a atividade e a identidade, que foi levado ao público através da principal obra do período: Psicologia Social: O homem em movimento, organizado por Sílvia Lane e Wanderley Codo em 1984. Completaram este trabalho a teoria da identidade como metamorfose, elaborada por Antonio da Costa Ciampa em tese de doutorado de 1987, A estória do Severino e a história da Severina; e a discussão sobre consciência realizada por Bader Sawaia no seu doutorado, A consciência em construção no trabalho de construção da existência, em 1987.

Com esse desenvolvimento teórico, pela primeira vez, criou-se, de fato, uma alternativa à psicologia social norte-americana. $\mathrm{O}$ mesmo movimento realizado por Florestan Fernandes, de busca da realidade social, do trabalho empírico, da busca de alternativas metodológica para se construir a base de uma teoria consistente, foi realizado por Sílvia Lane no campo da Psicologia Social. Em artigo comentando os cursos e programas de psicologia social no Brasil, ministrados entre 1983 e 1993, Sergio Ozella identifica a importância que o aporte teórico desenvolvido na PUC-SP ganhou neste período. Em 1983, os autores mais citados e indicados como leitura nos cursos de psicologia social, eram Aroldo Rodrigues (54 menções); J. L. Freedman (36); Solomon Asch (29); Krech, Crutchfield e Ballachey (29) e Sílvia Lane com o seu introdutório $O$ que é a Psicologia Social (22). Em 1993, Sílvia Lane e Wanderley Codo com Psicologia Social: O homem em movimento, recebem 63 menções, seguidos do livro Psicologia Social de Aroldo Rodrigues com 36. Em terceiro lugar $O$ que é a Psicologia Social com 28 menções. Foi o coroamento de um intenso e importante trabalho realizado por Sílvia durante todos aqueles anos, investindo na construção da Psicologia Social no Brasil e na América Latina.

Naqueles intensos anos 70 e 80 , com toda aquela movimentação e esforços para a renovação, ocorreu a construção da ABRAPSO em 1980. Reunindo professores da PUC-SP, orientandos do programa de pós-graduação e outros profissionais e professores de outras escolas, Sílvia Lane fundou a Associação Brasileira de Psicologia Social. Havia, naqueles anos, a ALAPSO Associação Latino-americana de Psicologia Social, mas era uma entidade sem representatividade, que servia apenas de espaço de projeção para alguns poucos que nela se mantinham, sem qualquer esforço de construção de uma Psicologia para a América Latina. Em 1979, aprovou-se no encontro da SIP (Sociedade Interamericana de Psicologia) no Peru, a proposta de criar associações nacionais, substituindo a ALAPSO. Ainda em 1979, quando Sílvia Lane retornou ao Brasil, organizou um Encontro de Psicologia Social e realizou reunião para debater a criação da ABRAPSO. "Segundo Sílvia, uma das principais realizações do encontro foi a de conscientizar os participantes psicólogos de que suas perplexidades, percebidas até então como sentimentos individuais, eram compartilhadas por cientistas de diversas áreas". (Sawaia, 2002, p. 66). Em 10 de julho de 1980, na Universidade Estadual do Rio de Janeiro (UERJ), foi fundada a ABRAPSO. "A criação da ABRAPSO é um marco decisivo na orientação da psicologia social brasileira em direção à problemática de nossa realidade sócio-econômica-política-cultural. Também reafirma a importância fundamental de Lane, que ficou na presidência nacional até 1983 ..." (Molon apud Sawaia, 2002, p. 67). A história da Psicologia Social no Brasil tem assim uma forte presença de Sílvia Lane. Esta história que caminha na direção do compromisso com a realidade brasileira e da América Latina e que em termos de produção teórica culmina com a produção da chamada Psicologia Social Sócio-Histórica.

Sílvia Lane parecia sempre saber para onde caminhar e para onde levar a Psicologia Social, mas todos aqueles que com ela conviveram sabem que ela "inventou junto", ou seja, prezou sempre os espaços de criação coletiva. Por isto, houvesse mais espaço para traçarmos todas as linhas do desenvolvimento da Psicologia Social no Brasil, a partir de Sílvia, os traços alcançariam a todos que hoje se encontram no campo de uma Psicologia Social comprometida e crítica. ${ }^{3}$

\section{Uma Psicologia Social Sócio-Histórica}

A Psicologia Social que veio a ser denominada sócio-histórica surgiu nesse processo de revisão e crítica com vistas à produção de um conhecimento comprometido com a transformação social. Como vimos, foram diversos os atores desse processo, que resultou em um conjunto de elaborações teóricas afinadas com a idéia da desnaturalização dos fenômenos sociais.

Entretanto, vimos também que Sílvia Lane se destacou nesse processo e conduziu um conjunto de pesquisas e elaborações conceituais que são identificadas como psicologia social sócio-histórica. 
Seus fundamentos epistemológicos, metodológicos e ontológicos já foram mencionados. Decorrem do materialismo histórico e dialético e permitem abordar os fenômenos sociais e psicológicos na sua historicidade. Também mencionamos anteriormente um recorte da obra teórica de Sílvia Lane, que nos permite perceber a coerente articulação entre suas proposições teóricas e práticas por meio da compreensão de duas importantes questões: a dialética subjetividade-objetividade; e a formação e mudança de valores.

A partir desses fundamentos, então, Sílvia Lane desenvolveu a concepção de uma subjetividade em processo dialético, numa dialética subjetividade-objetividade. Teve acesso à obra dos soviéticos Luria, Leontiev e Vigotski e, a partir deles, desenvolveu o estudo das categorias do psiquismo: atividade, consciência e identidade. Articulou seus estudos sobre linguagem e processo grupal à compreensão das categorias como processos constituídos por mediações. Trabalhou também, nessa perspectiva, com a teoria das representações sociais de Moscovici.

Uma pessoa é a sintese do particular e do universal, ou seja, sua individualidade se constitui, necessariamente, na relação objetiva com o seu meio físico, geográfico, histórico e social. que irão, através de suas ações, desenvolver, o psiquismo humano constituído, fundamentalmente, pelas categorias: consciência, atividade e afetividade, (trataremos da Identidade num segundo momento).

Empiricamente, podemos constatar as mediações constitutivas dessas categorias: as emoções, a linguagem e o pensamento, responsáveis pela subjetivaçãol objetivação do psiquismo humano.

A análise só estará completa se considerarmos o ser humano, ontogeneticamente, como um ser sócio-histórico, ou seja, ele se desenvolveu através de ferramentas inventadas e de uma linguagem articulada a fim de transmitir a utilidade dessas para os seu pares.

Estas relações se dão através da mediação de grupos sociais dos quais um indivíduo participa, necessariamente, a fim de garantir sua sobrevivência, assim, além de adquirir a linguagem produzida por esta sociedade, desenvolve o pensamento, os afetos e sentimentos. É neste processo de interação que se desenvolve a sua Identidade, como categoria constitutiva de seu psiquismo.

Indivíduo e Sociedade são inseparáveis, segundo a dialética, pois o particular contem em si o universal, deste modo, se desejamos conhecer cientificamente o ser humano, é necessário considerá-lo dentro do contexto histórico, inserido em um processo constante de subjetivação/objetivação.

Nosso organismo é estimulado a todo momento: percebemos, sentimos, reagimos, refletimos e agimos, objetivando a nossa subjetividade a qual por sua vez se transforma, num processo constante, de metamorfose, isto se não nos deixarmos cristalizar por papéis desempenhados sem uma reflexão crítica. (Lane, 2002, p. 12).

Nesta síntese, toda a riqueza das formulações teóricas de Sílvia Lane pode ser percebida. Estão aí colocadas as suas principais contribuições: devemos compreender o psiquismo como processo constante, um processo constituído na vida concreta, por meio das ações, vivências, experiências do indivíduo e por meio de suas relações. Processo contraditório, revelador da dinâmica entre a totalidade social e a particularidade das situações individuais, entre o universal e o singular das experiências humanas. E processo protagonizado por sujeitos históricos, que, por serem sujeitos trazem emoção, reflexão, ação, movimento.

A produção de Sílvia Lane não se desviou, em nenhum momento, de seu propósito maior: desenvolver uma psicologia que contribua com a transformação da sociedade. A compreensão dos aspectos psicológicos como constituídos em uma dialética subjetividade-objetividade traz a possibilidade de superar explicações que apenas justapõem indivíduo e sociedade e permite que, ao se falar do sujeito, fale-se, necessariamente, da realidade social da qual participa. E compreender que ambos, sujeito e sociedade estão em um movimento que tem por base as contradições do processo histórico, significa poder apontar as possibilidades de transformação.

O aprofundamento dessa perspectiva, podemos dizer, encontra-se com outra vertente importante da obra de Sílvia Lane: como se constituem e qual o papel dos valores no processo subjetivo-objetivo ou na relação indivíduo-sociedade. Seus estudos iniciais sobre a dimensão valorativa presente nos significados das palavras, investigações realizadas com o diferencial semântico de Osgood, ampliaram-se com as noções de significado social e sentido pessoal, desenvolvidas a partir de Leontiev e Vigotski, no estudo da linguagem como mediação no processo atividade-consciência. Posteriormente, essas investigações desenvolveram-se com os estudos sobre emoções e a postulação da categoria afetividade.

Em relação à linguagem, Ś́lvia Lane sempre apontou a necessidade de se considerar os aspectos ideológicos presentes na construção de significados. Dessa maneira, pôde desenvolver a compreensão da linguagem como mediação no processo de consciência fazendo clara referência ao lugar social ocupado pelo indivíduo e às determinações históricas a que está sujeito. Ao mesmo tempo, considerar o indivíduo também como produtor de sentidos recoloca-o em posição ativa, mesmo que de maneira contraditória. Na verdade, a investigação da articulação entre significados sociais e sentidos pessoais 
possibilitada pela atividade, concretiza a investigação da dialética subjetividade-objetividade.

\begin{abstract}
A análise que Leontiev faz da aprendizagem da língua materna aponta para dois processos que se interligam necessariamente: se, por um lado, os significados atribuídos às palavras são produzidos pela coletividade no seu processar históricos e no desenvolvimento de sua consciência social e, como tal, se subordinam às leis histórico-sociais, por outro, os significados se processam e transformam através de atividades e pensamentos de indivíduos concretos e assim se individualizam, se 'subjetivam', na medida em que 'retornam' para a objetividade sensorial do mundo que os cerca, através das ações que eles desenvolvem concretamente.
\end{abstract}

Desta forma, os significados produzidos historicamente pelo grupo social adquirem, no âmbito do indivíduo, um 'sentido pessoal', ou seja, a palavra se relaciona com a realidade, com a própria vida e com os motivos de cada indivíduo. (Lane, 1984b, p. 32-33).

A linguagem, produção ao mesmo tempo social e individual é expressão da síntese e do movimento entre sujeito e realidade. Significado e sentido, como unidade de contrários, ao mesmo tempo revelam e possibilitam e concretizam a dialética subjetividade-objetividade. $\mathrm{O}$ desenvolvimento dos estudos sobre as categorias do psiquismo possibilitou que Sílvia Lane avançasse na compreensão da emoção e da criatividade. São os desafios que sempre se propôs a enfrentar e de maneira coerente: é necessário compreender o que permite ao homem se implicar, se reconhecer como sujeito, compreender as determinações a que está sujeito e as formas de agir sobre elas. É necessário compreender o que impede e o que permite ao homem agir para transformar a realidade de forma libertadora e emancipadora.

Por isso, a necessidade de pesquisar como surgem, se mantém e se modificam as emoções. A afetividade é também categoria fundamental do psiquismo, formulação de Sílvia Lane para indicar a ligação do indivíduo com o contexto social para além de um reconhecimento cognitivo.

O ser humano é um todo - fisiologia e psicologia são manifestações de uma mesma totalidade. Assim como as funções fisiológicas estão integradas, também as psicológicas interagem, desenvolvendo funções psiconeurológicas superiores que ampliam a capacidade humana. Em síntese, ele é produto de um longo processo histórico, no qual as mediações das emoções, da linguagem, do pensamento e dos grupos sociais constituem a subjetividade: consciência, atividade, afetividade e identidade.

Essa subjetividade, em sua unidade dialética com a objetividade, permite o desenvolvimento de valores morais, éticos e estéticos. (Lane, 1999, p. 119).
Exatamente por trazer a questão dos valores e sua constituição na dialética subjetividade-objetividade, sem perder de vista a inserção histórica do indivíduo é que Sílvia Lane realizou uma psicologia social que desvendou a unidade contraditória entre indivíduo e sociedade. A psicologia social sócio-histórica coloca-se como uma psicologia que não aceita o que constata, mas uma psicologia social que se posiciona, porque o reconhecimento da historicidade dos fenômenos que estuda assim o permite.

Coerente com a visão de que o conhecimento e a intenção prática em relação ao objeto não se separam, Sílvia Lane nos deixou desafios: avançar na pesquisa sobre a maneira como os indivíduos se implicam ou não com sua própria realidade é compromisso ético de quem se dedica à Psicologia.

Procurei entender, primeiro, como se formam os valores nos seres humanos, como eles se dão e orientam o cotidiano das pessoas. . . Esse é o desafio, esmiuçar como se dão os processos, não só na formação de valores, mas na mudança de valores. Sem esquecer que eles vêm carregados de muita história - a familiar, a social - e não é fácil mudar. A não ser que a pessoa assuma, realmente, uma reflexão crítica . . . Aí surge outro dilema, outra contradição: entre imaginação $e$ fantasia. A fantasia leva à alienação, é destrutiva, porque perde os vínculos com o real, enquanto que a imaginação tem os pés no real, no cotidiano. Outro desafio que surgiu há pouco tempo é a apatia, o desinteresse. Alguém indiferente às coisas está negando a própria vida, a emoção, o afeto! Isso é terrível! Como se forma um sentimento de indiferença? Ele é a morte, é virar um robô. São desafios nos quais temos que nos aprofundar, pesquisar. Se assumirmos que a transformação social só se dará eticamente, quem mais do que nós, psicólogos, tem essa arma na mão? É exatamente esse pensar ético que deve estar presente onde o psicólogo estiver atuando. (Lane, 2000).

Um pensar ético, um compromisso ético que alia o conhecimento com a ação. A proposta, o desafio de pesquisar para poder interferir, atuar para que os homens sejam sujeitos, não sejam robôs. Para que os homens se envolvam, não sejam indiferentes. $O$ referencial da psicologia social sócio-histórica, ao apontar a historicidade constitutiva dos fenômenos, ao apontar sua gênese contraditória permite apontar ações de superação, permite usar o conhecimento de forma posicionada.

\section{Uma Psicologia Atenta ao Contexto Social ou "Toda a Psicologia é Social" 4}

Cabe destacar, ainda, a questão do "social" que caracteriza e nomeia a Psicologia de Sílvia Lane. A noção teórica que nos faz colocar o epíteto de social na psicologia merece atenção de todos nós, pois ele não tem o mesmo sentido em todos os lugares onde aparece. 
É fácil que ocorra nas áreas de conhecimento a aceitação de nomenclaturas que refletem mais a acomodação dos interesses de seus construtores do que a clareza na delimitação de suas possibilidades e obrigações. Tal é o caso, por exemplo, da Psicologia Social estadunidense que, a despeito de contar uma enorme produção de artigos e livros, ainda na década de setenta tinha vários autores que afirmavam ser prejudicial tentar qualquer definição de seu escopo porque isso tiraria a liberdade das pessoas que estavam engajadas na sua construção. Isto é, para essas pessoas a indefinição era a forma de manter aquela Psicologia Social.

Pois é possível afirmar que tenha sido exatamente a exigência de esclarecer o que seria o social na psicologia que tenha gerado no Brasil a possibilidade de desenvolvimentos que diferenciaram de forma tão significativa seus contornos e projetos de pesquisa e de atuação. Essa exigência permitiu que a inserção do grupo de trabalho que Sílvia Lane compunha, ganhasse uma nova qualidade, pois foi diferente daquela mais comum nos grupos então atuantes no Brasil. Não se tratava de aplicar ou proceder a algum desenvolvimento marginal na Psicologia, decorrente da apropriação do pensamento psicológico encontrado pronto em outros países. Era preciso indicar claramente a partir de qual solo se estava trabalhando e, já aí, produzir algo novo, uma vez que adequado a este solo específico.

A inserção de seu grupo de trabalho foi diferente porque eles se comportavam como construtores da Psicologia. A exigência de nomear sua produção pode ter sido importante para que o comportamento desse grupo não fosse reprodutor, ou aplicador, ou pregador, ou repetidor, ou defensor de algo que lhes havia sido mandado desde algum lugar supostamente especial onde a Psicologia brotava de forma mais espontânea do que nas terras tupiniquins. A Psicologia era algo que precisava ser construído e essa tarefa cabia a cada uma das pessoas que participavam desse debate.

Claro que muitas das iniciativas surgiram a partir do exercício da crítica ao conhecimento que era encontrado pronto. A partir desse exercício crítico, houve recusas de várias ordens às concepções advindas de outras plagas. Por exemplo, a recusa de que o epíteto "social" fosse simplesmente agregado aos diferentes tópicos abordados pela Psicologia tradicional. Assim, para ser social não bastava tratar de uma possível "percepção social", consoante com uma Psicologia que por tanto tempo estudara um conceito que ela denominava de percepção individual. Também não bastava colher para exame algum evento grupal e aplicar sobre ele um procedimento de exame estabelecido para fenômenos individuais.

Nos debates em sala de aula, na busca de encontrar elementos fundamentais dessa perspectiva social, houve algum momento de radicalização, talvez pueril, "aparentemente" desnecessária, nessa caracterização. Tal é o caso da exigência de que a produção dessa psicologia tivesse que ocorrer sempre de forma coletiva. Assim, para ser coerente com as exigências de construção de uma psicologia social, seria preciso que seus textos fossem produzidos de forma claramente social e grupal. $\mathrm{O}$ termo "aparentemente" vem entre aspas porque parece refletir uma exigência importante, ainda que formulada em sala de aula de forma pouco precisa, qual seja a de que a instauração de uma psicologia efetivamente comprometida com as necessidades do povo brasileiro seria tarefa de coletivos de psicólogos comprometidos com essa perspectiva.

Vale ressaltar um elemento caracterizador desse social que resume o que se apresenta aqui. Tratava-se de situar cada evento, cada pessoa, cada iniciativa em seu contexto social. O social não seria simplesmente um acréscimo ao que a Psicologia já sabia fazer. Tampouco significava uma defenestração do que fora produzido até então. Ele teria que ser uma fonte de renovação dessa Psicologia, sua capacitação para enfrentar os desafios que a sociedade the propunha e produzir respostas às questões que realidade lhe impunha.

Nessa perspectiva, o psicólogo social não seria somente aquele que trabalharia com problemas ou situações de caráter social ou grupal. Um psicólogo clínico (em atendimento individual, em consultório particular), seria também um psicólogo social. Para isso, bastaria que ele procedesse em seu trabalho ao exercício de contextualização do seu cliente no seu momento social e histórico. $\mathrm{Na}$ medida em que as fontes explicativas e os resultados obtidos tivessem um caráter de habilitação de cada pessoa para atuar e transformar sua realidade (isto é, participar dos processos de transformação), esse trabalho poderia ser considerado como de psicologia social.

A atenção ao contexto do fazer humano foi uma forma de inserir no campo de visão da Psicologia aquilo que nos anos setenta era chamado de "realidade brasileira". Diante do reconhecimento de que a Psicologia se desenvolvera quase sempre sem atentar para as necessidades, virtudes e problemas vividos pela maioria da população brasileira, o contexto a que se deveria dar atenção era o contexto econômico, histórico e social onde viviam os brasileiros.

Neste sentido é que a expressão "toda a psicologia é social" ganha uma possibilidade de compreensão fértil para o projeto de construção de uma psicologia social efetivamente adequada aos povos brasileiro e latino-americano.

É possível afirmar que essa compreensão, do que seja o social na Psicologia, tenha se mantido válida até o fim da vida de Sílvia Lane. Seu entusiasmo e disposição para 
colaboração, nas mais diferentes iniciativas, se reacenderam quando percebeu que um movimento, com essas características, ganhava espaço na Psicologia Brasileira. Ao longo da última década, Sílvia não poupou esforços para colaborar.

\section{Uma Psicologia com Compromisso Social: Uma Herança de Sílvia Lane}

Para finalizarmos este artigo, cabe fazer a relação da Psicologia Social produzida sob a orientação e empenho da Profa. Sílvia Lane, com o projeto, hoje existente, de uma Psicologia com compromisso social.

Sílvia Lane tem sua produção e seu exercício, como professora, marcados pela certeza de que a Psicologia deveria se produzir de forma a ser útil para a transformação da realidade social em nossos países de Terceiro Mundo. Perseguiu isto como uma obsessão e sem descuidar de dar-lhe forma acadêmica e rigor científico. Buscou métodos, instrumentos, conceitos e teorias que pudessem dar conta disto. Não se acomodou e nem mesmo se satisfez com o que estava posto em cada momento. Cada certeza era o início de um novo momento de dúvidas e buscas. Sílvia Lane dialogou com todos; aceitou desafios e acolheu sugestões e iniciativas de seus alunos. Produziu coletivamente com eles, talvez seus principais interlocutores. A única certeza de que nunca abriu mão foi a da necessidade da produção de uma ciência com compromisso social. Nunca se importou com rótulos e com passeios por diferentes teorias, porque buscava outra coisa: um conhecimento capaz de falar da vida vivida e de apresentar possibilidades de contribuição para a transformação das condições de vida na busca da dignidade. Qualquer tema poderia ser eixo das pesquisas que seus orientandos traziam, mas todos deveriam the responder: qual a realidade que quero contribuir para mudar?

Esta intransigência ética marcou seu trabalho de pesquisadora e professora. Deixou para a Psicologia uma obra importante nesta direção. Mas, mais do que isto, ela deixou um conjunto de psicólogos e pesquisadores, em sua maioria identificados com a ABRAPSO, que buscam de vários lugares teóricos produzir uma nova Psicologia: uma psicologia com compromisso social com a realidade brasileira e da América Latina. Isto nos permite afirmar que Sílvia Lane mudou os rumos da Psicologia no Brasil e permitiu a construção de um novo projeto para a ciência e para a profissão.

\section{Notas}

1. Para uma crítica profunda desse modelo veja Bock, Ana M. B. (1997). As aventuras do Barão de Münchhausen na Psicologia: Um estudo sobre o significado do fenômeno psicológico na categoria dos psicólogos. Tese de doutorado não- publicada, Programa de Psicologia Social, Pontifícia Universidade Católica de São Paulo.

2. Veja Bonfim, Elizabeth. Psicologia Social no Brasil; Freitas, $\mathrm{M}^{\mathrm{a}}$ de Fátima Q. (1996, jan./jun.). Contribuições da Psicologia Social e Psicologia Política ao desenvolvimento da Psicologia Social Comunitária: Os paradigmas de Sílvia Lane, Ignacio Martín-Baró e Maritza Montero. Psicologia \& Sociedade, 1(8), e também os próprios Anais do I Encontro Regional de Psicologia na Comunidade (1981, set.), São Paulo, ABRAPSO, no qual Alberto Abib Andery relata a experiência dos estágio em Osasco.

3. Dados sobre estas iniciativas podem ser encontrados em publicação de Bader Sawaia (2002). Sílvia Lane: Vol. 8. Coleção Pioneiros da Psicologia Brasileira, de iniciativa do Conselho Federal de Psicologia, Brasília, DF: Imago.

4. Esta afirmação citada entre aspas está presente em texto de Sílvia Lane publicado em 1984 -Psicologia Social: $O$ homem em movimento - pela Ed. Brasiliense, organizado por ela e por Wanderley Codo (Lane, 1984a).

\section{Referências}

Ciampa, A. C. (1987). A estória do Severino e a história de Severina: Um ensaio de Psicologia Social. São Paulo, SP: Brasiliense.

Lane, S. T. M. (1984a). A Psicologia Social e uma nova concepção de homem para a Psicologia. In S. T. M. Lane \& W. Codo (Eds.), Psicologia Social: O homem em movimento (pp. 10-19). São Paulo, SP: Brasiliense.

Lane, S. T. M. (1984b). Linguagem, pensamento e representações sociais. In S. T. M. Lane \& W. Codo (Eds.), Psicologia Social: O homem em movimento (pp. 32-39). São Paulo, SP: Brasiliense.

Lane, S. T. M. (1999). Os fundamentos teóricos e conclusões. In S. T. M. Lane \& Y. Araújo (Eds.), Arqueologia das emoções (pp. 11-33, 119-120). Petrópolis, RJ: Vozes.

Lane, S. T. M. (2000, maio/jun.). Diálogos: Uma psicologia para transformar a sociedade [Entrevista]. PSI Jornal de Psicologia, São Paulo, 18(122), 4-6.

Lane, S. T. M. (2002). A dialética da subjetividade versus a objetividade. In O. Furtado, Odair \& F. González-Rey (Eds.), Por uma epistemologia da subjetividade: Um debate entre a teoria sócio-histórica e a teoria das representações sociais (pp. 11-17). São Paulo, SP: Casa do Psicólogo.

Lane, S. T. M., \& Sawaia, B. B. (1995). La Psicologia Social Comunitária en Brasil. In E. Wiesenfeld \& E. Sánchez (Eds.), Psicologia Social Comunitaria: contribuciones Latinoamericanas (pp. 69-116). Caracas, Venezuela: Fondo Tropykos.

Sawaia, B. (1987). A consciência em construção no trabalho de construção da existência. Tese de Doutorado não-publicada, Pontifícia Universidade Católica de São Paulo.

Sawaia, B. (2002). Sílvia Lane: Vol. 8. Coleção Pioneiros da Psicologia Brasileira. Rio de Janeiro, RJ: Imago. 
Ana Mercês Bahia Bock é Psicóloga e Professora titular da Faculdade de Psicologia da Pontifícia Universidade Católica de São Paulo (PUC-SP), ministrando aulas na graduação e no programa de Pós-Graduação em

Educação: psicologia da educação. É presidente do Conselho Federal de Psicologia (CFP) gestão 2004/2007.

Foi orientanda no mestrado e no doutorado da Profa. Sílvia Lane. Endereço para correspondência: Pontifícia Universidade Católica de São Paulo, Rua Monte Alegre, 984, São Paulo, SP, 05014-001.

psicopuc@pucsp.br

Marcos Ribeiro Ferreira é Psicólogo e Professor aposentado da Universidade Federal de Santa Catarina

(UFSC). Formou-se em Psicologia e obteve título de doutor na PUC-SP. É presidente da Associação Brasileira de Ensino de Psicologia gestão 2005/2007. Endereço para correspondência: Universidade Federal de Santa Catarina,

Centro de Filosofia e Ciências Humanas, Departamento de Psicologia, Florianópolis, SC, 88040-970.

psico@cfh.ufsc.br

Maria da Graça M. Gonçalves é Psicóloga, Professora de Psicologia Social na Faculdade de Psicologia da PUC-SP; diretora da Faculdade de Psicologia da PUC-SP, gestões 2001/2005; 2005/2009; presidente do Conselho Regional de Psicologia (CRP) gestão 2004/2007. Foi orientanda da Profa. Sílvia Lane no doutorado.

Odair Furtado é Psicólogo e Professor associado na Faculdade de Psicologia da PUC-SP, ministrando aulas na graduação e na Pós-Graduação em Psicologia Social. Foi orientando da Profa. Sílvia Lane. Foi presidente do CFP gestão 2001/2004.

\section{Sílvia Lane e o Projeto do "Compromisso Social da Psicologia"}

Ana Mercês Bahia Bock, Marcos Ribeiro Ferreira, Maria da Graça M. Gonçalves, Odair Furtado

Recebido: 23/05/2007

$1^{\text {a }}$ revisão: $20 / 07 / 2007$

Aceite final: 14/09/2007 